\title{
Entoepidemiology of Chagas disease in northwest São Paulo and cytogenetic analysis of its main vector, Triatoma sordida (Hemiptera: Triatominae)
}

R. Silistino-Souza ${ }^{1}$, K.C.C. Alevi ${ }^{1}$, N.F.C. Castro ${ }^{1}$, M.N. Freitas ${ }^{1}$, M.D. Papa ${ }^{2}$, S.A.S. Scandar ${ }^{2}$, R.R. Bestetti ${ }^{3}$, J.A. Rosa $^{4}$ and M.T.V. Azeredo-Oliveira ${ }^{1}$

${ }^{1}$ Laboratório de Biologia Celular, Departamento de Biologia, Instituto de Biociências, Letras e Ciências Exatas, Universidade Estadual Paulista "Júlio de Mesquita Filho", UNESP/IBILCE, São José do Rio Preto, SP, Brasil

${ }^{2}$ Superintendência de Controle de Doenças Endêmicas - SUCEN, Regional 8, São José do Rio Preto, SP, Brasil

${ }^{3}$ Departamento de Cardiologia e Cirurgia Cardiovascular, Hospital de Base, São José do Rio Preto, SP, Brasil

${ }^{4}$ Laboratório de Parasitologia, Departamento de Ciências Biológicas, Faculdade de Ciências Farmacêuticas,

Universidade Estadual Paulista "Júlio de Mesquita Filho",

UNESP/FCFAR, Araraquara, SP, Brasil

Corresponding author: R. Silistino-Souza

E-mail: rosanass@ibilce.unesp.br

Genet. Mol. Res. 12 (4): 5810-5819 (2013)

Received January 27, 2013

Accepted August 7, 2013

Published November 22, 2013

DOI http://dx.doi.org/10.4238/2013.November.22.8

ABSTRACT. One century after the discovery of Chagas disease, it is still considered as a major health problem, causing more deaths in the Americas than any other parasitic disease. The northwest region of São Paulo, a macro-region that includes cities with a high-quality of life, has particularly high rates of Chagas disease. Therefore, this study aimed to assess the number of patients with Chagas disease, and to identify the triatomine fauna in the northwest region of São Paulo 
State, and to cytogenetically analyze Triatoma sordida mutants, thus providing new knowledge to control these species and avoid possible infections by Chagas disease. A total of 700 Chagas patients of both genders and variable age, who were born in and residents of the northwest region of the State of São Paulo were recruited for this study. Regarding the entoepidemiological fauna, both T. sordida and Rhodnius neglectus were captured from 2004 to 2011 in the northwest region of the São Paulo; however, T. sordida was the predominant species. Some of these collected triatomines were infected by Trypanosoma cruzi in several developmental stages. Furthermore, the lactoacetic orcein method was used for cytogenetic analysis. Several abnormalities were observed during meiosis of the $T$. sordida mutants, including condensed chromosomes with no chiasma, chromatin bridges between the autosomes, and some non-pairing homologous chromosomes. Thus, our study suggests that Chagas disease is currently not under control in Brazil. Furthermore, we suggest that cryptic speciation may be occurring in populations of T. sordida of Brazil. Further studies are necessary to understand the mechanisms behind these phenomena.

Key words: Chagas disease; Entoepidemiology; Rhodnius neglectus; Mutants; Cryptic speciation

\section{INTRODUCTION}

One century after the discovery of Chagas disease, it remains a major public health problem in Latin America, causing more deaths than any other parasitic disease (Guerri-Guttenberg et al., 2008). Chagas has spread in North America and Europe due to the migration of infected individuals, indicating the globalization of Chagas disease (Guerri-Guttenberg et al., 2008; Tanowitz et al., 2011). It is estimated that there are approximately 15 million people infected with Chagas disease worldwide, with an incidence of 50,000 to 200,000 new cases per year, and an additional 13 million people are likely unaware that they are infected with the parasite (Souza and Chaves, 2009). In Brazil, Chagas infection has already afflicted approximately 2.5 million individuals (Tarleton et al., 2007). These data show the urgent need to invest in means to effectively control Chagas disease.

Chagas disease is caused by the parasite Trypanosoma cruzi, which is transmitted to humans through the feces of sucking bugs. Triatomine "sucking bugs", the main transmitters of the parasite, are hematophagous insects that belong to the order Hemiptera, the suborder Heteroptera, the family Reduviidae, and the subfamily Triatominae. Currently, there are descriptions of 145 triatomine species distributed among 18 genera (Alevi et al., 2013a). There are 61 triatomine species in Brazil, and all species of this subfamily are potential transmitters of T. cruzi (Vallejo et al., 2009). Triatoma infestans was the most important transmitter of Chagas disease in Brazil until recently (Silveira and Dias, 2011).

The northwest region of São Paulo, which is comprised of cities with relatively high income and quality of life, presents high rates of chronic Chagas disease. Although triatomines are monitored systematically in the municipalities of this region by the Superintendent of Endemic Disease Control (SUCEN), Chagas disease remains a concern for health agencies. 
Nonetheless, autochtone cases of Chagas disease have not been identified in São Paulo State over the last few decades.

The Ministry of Health received international certification for the elimination of Chagas disease transmission by T. infestans from the Pan American Health Organization in 2006. However, the elimination of only one type of vector does not necessarily maintain control over the disease, since elimination means only a momentary interruption in transmission, whereas eradication is a definitive interruption (Galvão et al., 2003). Furthermore, continuous eradication surveillance should be performed to avoid the resurgence of Chagas disease, as observed in Venezuela (Bonfante-Cabarcas et al., 2011). Thus, if the remaining chagasic foci in several Brazilian states are not eradicated, the disease may return, as has occurred with dengue and malaria, invalidating all that has already been accomplished by national eradication campaigns (Galvão et al., 2003).

Cytogenetic analyses have contributed to the correct classification of triatomines (Ueshima, 1966; Pérez et al., 1992; Panzera et al., 1995, 1997; Alevi et al., 2012a,b, 2013b,c,d,e). The correct classification of triatomines enables differentiation of species of primary importance from those of minor importance, since some species are currently in the process of domiciliation, i.e., leaving their natural habitats and settling in urban environments such as indoors and in the peridomicile (Dias and Scholfield, 1998).

The combination of field research and new analytical tools are opening research paths that may lead to opportunities to improve the effective control of Chagas disease transmission (Dias et al., 2002; Miles et al., 2003). Therefore, the present study aimed to cytogenetically analyze T. sordida mutants, to assess the number of patients carrying Chagas disease, and to identify the triatomine fauna in the northwest region of São Paulo State, thus providing new information for the control of these species in order to avoid possible infections.

\section{MATERIAL AND METHODS}

Data of the triatomine fauna from the São Paulo State region were obtained through population reports received by the SUCEN of São José do Rio Preto between 2004 and 2011. Triatomines are systematically monitored by SUCEN in all of the municipalities within the agency's area of responsibility, since such surveillance is essential to avoid new cases of the disease. The insects found within this region were collected and sent for laboratory testing in order to identify possible cases of triatomines infected by the parasite $T$. cruzi. After inspection of each notification site, the SUCEN performed nebulizations with insecticides. For cytogenetic analysis, seminiferous tubules of two adult male mutants (with morphological changes) of $T$. sordida from the "Insectarium of Triatominae", installed in UNESP/FCFAR, Araraquara, São Paulo, were shredded, smashed, and mounted onto a slide in liquid nitrogen. Slides were then stained with lacto-acetic orcein using the cytogenetic technique (De Vaio et al., 1985, modifications according to Alevi et al., 2012b).

\section{RESULTS}

\section{Chagas disease patients}

The medical charts of patients routinely followed as outpatients of the Cardiomyopathy Service of the Hospital de Base of São José do Rio Preto/SP from 1995 to 2009 were reviewed. Seven hundred patients were diagnosed with chronic Chagas disease, indicating that Chagas dis- 
ease is the highest contributor to cardiomyopathy at the institution. Patients of both genders that varied in age showed a significant increase in Chagas disease from 0 to 60 years, and younger age groups (between 0 and 50 years) presented with Chagas disease more frequently (Figure 1).

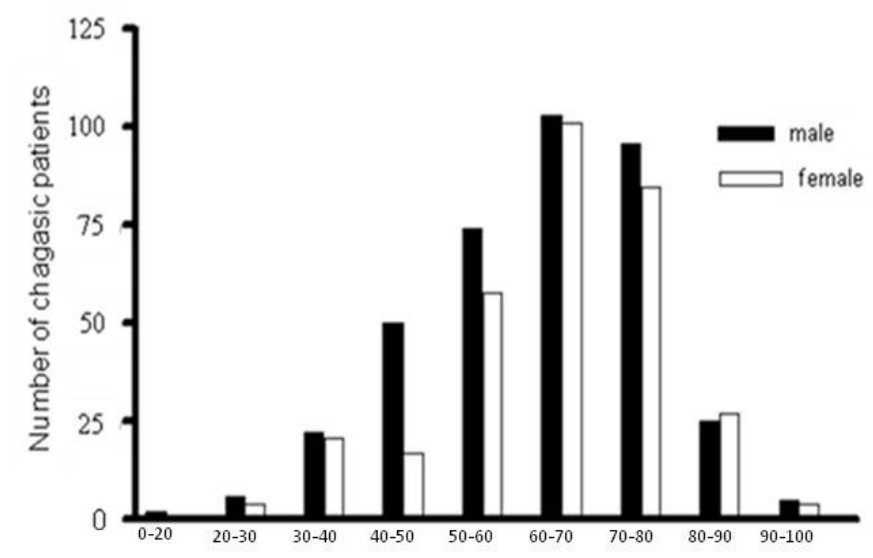

Figure 1. Relationship of the patients by age and gender. Source: Hospital de Base de São José do Rio Preto, SP.

\section{Distribution of the Triatominae fauna}

The main areas of incidence and capture of triatomines in the northwest region of the São Paulo State were the cities of São José do Rio Preto $\left(49^{\circ} 22^{\prime} \mathrm{S} ; 20^{\circ} 49^{\prime} \mathrm{W}\right)$, Catanduva $\left(21^{\circ} 08^{\prime} \mathrm{S} ; 48^{\circ} 58^{\prime} \mathrm{W}\right)$, Jales $\left(20^{\circ} 16^{\prime} \mathrm{S} ; 50^{\circ} 32^{\prime} \mathrm{W}\right)$, Fernandópolis $\left(20^{\circ} 17^{\prime} \mathrm{S} ; 50^{\circ} 14^{\prime} \mathrm{W}\right)$, and Votuporanga $\left(20^{\circ} 25^{\prime} \mathrm{S} ; 49^{\circ} 58^{\prime} \mathrm{W}\right)$ (Figure 2$)$, from which 2871 triatomine specimens were reported from 2004 to 2011 (Table 1). There was a noticeable peak in 2005, followed by a gradual decline of reports in subsequent years (Table 1). Subsequent inspections of these reporting houses in the northwest region resulted in the capture of a total of 14,583 triatomine species (Tables 2 and 3). The species observed in these areas were T. sordida and Rhodnius neglectus, presenting respective averages of 14,017 and 566 specimens captured during this period (Table 2).

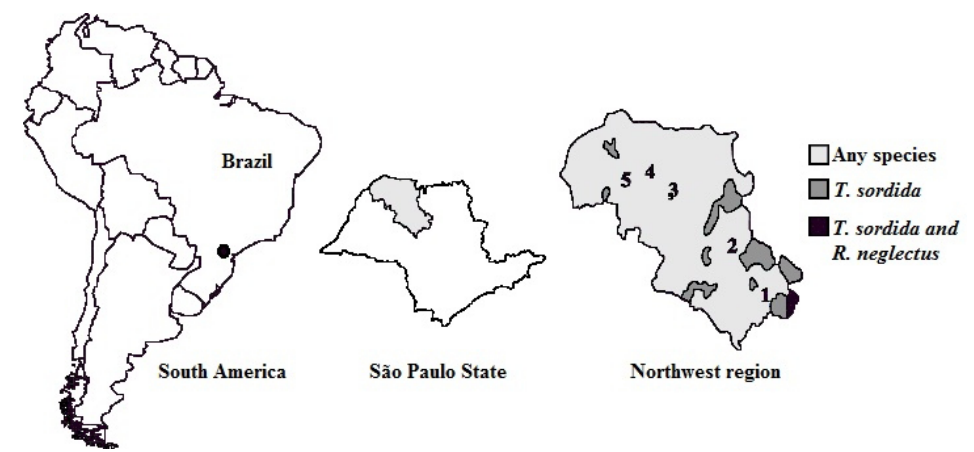

Figure 2. Map of South America showing São Paulo State highlighting the northwest region including the main cities with incidence of triatomine identified in region (Triatoma sordida and Rhodnius neglectus). São Paulo State; Main cities: 1: Catanduva $\left(21^{\circ}, 08^{\prime} \mathrm{S} ; 48^{\circ}, 58^{\prime} \mathrm{W}^{\prime}\right)$; 2: São José do Rio Preto $\left(20^{\circ}, 49^{\prime} \mathrm{S} ; 4^{\circ}, 22^{\prime} \mathrm{W}\right)$; 3 : Votuporanga $\left(20^{\circ}, 25^{\prime} \mathrm{S} ; 4^{\circ}, 58^{\prime} \mathrm{W}\right)$; 4: Fernandópolis $\left(20^{\circ}, 17^{\prime} \mathrm{S} ; 50^{\circ}, 14^{\prime} \mathrm{W}\right)$ and 5: Jales $\left(20^{\circ}, 16^{\prime} \mathrm{S} ; 50^{\circ} 32^{\prime} \mathrm{W}\right)$. 
Table 1. Index of triatomine reports in northwest São Paulo State (2004 to 2011).

\begin{tabular}{lc}
\hline Year & Triatomine reports $(\mathrm{N}=2871)$ \\
\hline 2004 & 211 \\
2005 & 772 \\
2006 & 427 \\
2007 & 499 \\
2008 & 436 \\
2009 & 232 \\
2010 & 158 \\
2011 & 136 \\
\hline
\end{tabular}

Source: SUCEN (Superintendency of Endemy Control), 2012.

Table 2. Ecotope of the main triatomine species $(\mathrm{N}=14,583)$ captured in the northwest region (2004 to 2011).

\begin{tabular}{|c|c|c|c|c|c|c|c|c|}
\hline \multirow[t]{3}{*}{ Species } & \multicolumn{8}{|c|}{ Ecotope of the main triatomine species } \\
\hline & \multicolumn{4}{|c|}{ Intradomiciliary } & \multicolumn{4}{|c|}{ Peridomiciliary } \\
\hline & Eaves & Kitchen & Bedroom & Living room & Roof of the house & External roof & Around the house & Total \\
\hline Triatoma sordida & 547 & 491 & 1503 & 1571 & 106 & 124 & 9675 & 14,017 \\
\hline Rhodnius neglectus & 15 & 73 & 208 & 207 & 2 & 4 & 57 & 566 \\
\hline
\end{tabular}

Source: SUCEN (Superintendency of Endemy Control), 2012.

Table 3. List of artificial ecotopes found at locations of triatomine infestation.

\begin{tabular}{lcccccccr}
\hline Species & Dog & Chicken & Skunk & Cat & Rodent & Other birds & Other animals & Nothing contained \\
\hline Triatoma sordida & 25 & 7408 & 171 & 40 & 898 & 1820 & 89 & 4313 \\
Rhodnius neglectus & - & 56 & - & - & 1 & 36 & 3 & 593 \\
\hline
\end{tabular}

Source: SUCEN (Superintendency of Endemy Control), 2012.

\section{Ecotopes}

Several ecotopes of the triatomine species were captured in these areas, including intradomiciliary and peridomiciliary regions, as well as in the external area of the house (Table 2 ), bird nests, and domestic animal shelters (Table 3 ). In the intradomiciliary and peridomiciliary environments, $R$. neglectus was in lower frequency than $T$. sordida, which was in highest frequency in peridomiciliary environments (Table 2). R. neglectus was reported at higher frequencies in intradomiciliary environments than in the external and peridomiciliary areas, with the highest incidence in bedrooms and living rooms (Table 2). Triatomines were also found in the external environment (external roof) and around the house (Table 2). The frequency of T. sordida in artificial ecotopes was highest in henneries, although it was found in all animal nests and shelters. $R$. neglectus was also observed in henneries and bird nests, but was not frequent in any other artificial ecotope (Table 3).

\section{Triatomines of the northwest region of São Paulo State}

T. sordida was the most abundant species in the northwest region of the São Paulo State during the period of 2004 to 2011 at all reporting locations; however, both species, $T$. sordida and $R$. neglectus, were frequently encountered at most of the collection sites (Tables 2 and 3). Specimens of T. sordida captured were adult males and females, as well as nymphs 
of all developmental stages. Conversely, the captured individuals of $R$. neglectus represented only adult males and females and nymphs of the third and fifth stages (Table 4). Adult females of T. sordida and R. neglectus were captured in higher numbers when compared to the other development stages. Three adult females and one adult male in the fifth stage of $T$. sordida were positive for the parasite (Table 4). However, none of the captured $R$. neglectus individuals were infected by the parasite (Table 4). Two resident men of the infestation sites, aged 54 and 75 years, tested positive for the parasite based on serological analysis.

Table 4. Development stages of captured triatomine and infected by Trypanosoma cruzi (2004 to 2011).

\begin{tabular}{|c|c|c|c|c|c|c|c|c|c|c|c|c|c|c|}
\hline \multirow[t]{2}{*}{ Species } & \multicolumn{2}{|c|}{ Male } & \multicolumn{2}{|c|}{ Female } & \multicolumn{2}{|c|}{ 1st stage } & \multicolumn{2}{|c|}{ 2nd stage } & \multicolumn{2}{|c|}{ 3rd stage } & \multicolumn{2}{|c|}{ 4th stage } & \multicolumn{2}{|c|}{ 5th stage } \\
\hline & $\mathrm{CT}$ & $\bar{I}$ & $\mathrm{CT}$ & I & $\mathrm{CT}$ & $\bar{I}$ & $\mathrm{CT}$ & I & $\mathrm{CT}$ & I & $\mathrm{CT}$ & I & $\mathrm{CT}$ & I \\
\hline Tria & 2532 & 1 & 4200 & 4 & 696 & - & 1177 & - & 1637 & - & 1954 & - & 2568 & 1 \\
\hline Rhodnius neglectus & 279 & - & 402 & - & - & - & - & - & 2 & - & - & - & 6 & - \\
\hline
\end{tabular}

Captured triatomine (CT) and those infected (I) by T. cruzi. Source: SUCEN (Superintendency of Endemy Control), 2012.

\section{Cytogenetic analysis}

The lacto-acetic orcein technique revealed peculiarities of the T. sordida mutants during meiosis. During the initial diffuse stage, large heteropycnotic chromocenters were visible (Figure 3A and B; arrows). In the final diffuse stage (diplotene), some autosomes were highly heteropycnotic and had not undergone crossing over (Figure 3C; arrows). In the diakinesis stage, we observed chromatin bridges between all chromosomes (Figure 3D, arrows). The metaphases showed many monovalent autosomes resulting from non-pairing between homologs (Figure 3E-H; arrows).

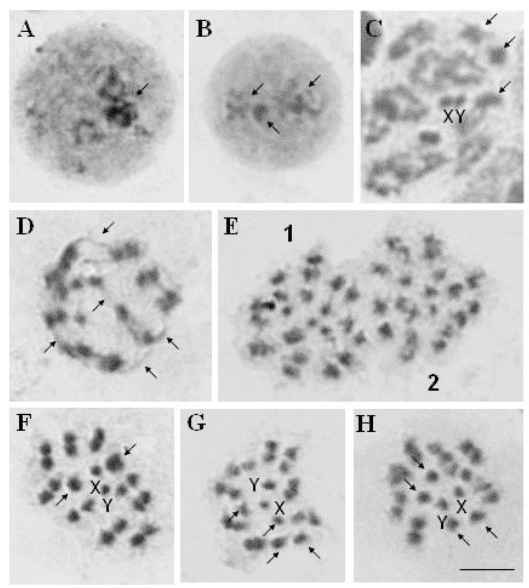

Figure 3. Meiosis in mutants the Triatoma sordida. A. and B. Initial diffuse stage. Note the large heteropycnotic chromocenters (arrows). C. Final diffuse stage (diplotene). Note that some autosomes were highly heteropycnotic and not undergone crossing over (arrows). D. Diakinesis. Note chromatin bridges between all chromosomes (arrows). E.-H. Metaphases. Note many autosomes monovalent resulting from not pairing between homologs (arrows). X: X sex chromosome, Y: Y sex chromosome. Bar $=10 \mu \mathrm{m}$. 


\section{DISCUSSION}

The main vectors of Chagas disease, triatomines, constitute an important study model for the comprehension of the development and control of this disease. Furthermore, biogeographical information has contributed to determining the geographic potential of the species acting as most efficient vectors, which can be useful for understanding chagasic transmission risk (Bestetti and Theodoropoulos, 2009).

The northwest region of São Paulo State presents a tropical climate with high temperatures throughout the year, cerrado vegetation, and extensive use of soil for agriculture. Biogeographical analyses have shown that constant environmental alterations caused by human activities, such as destruction of the vegetation by agriculture, may cause ecosystem imbalances that provoke changes in vector insect behavior. The current environmental pressures of deforestation, human population growth, and climate change require that strategies be readjusted to efficiently monitor and control the different vector species (Ostfeld et al., 2005).

In the northwest region of the São Paulo State, 14,583 triatomine species were captured between 2004 and 2011, represented by two species, T. sordida and R. neglectus. Although T. sordida was the most abundant species throughout the period analyzed, both species were frequently encountered at all collection sites. The results also showed the presence of $T$. sordida and $R$. neglectus infected by the parasite $T$. cruzi, in addition to humans carrying the Chagas disease. Collection of T. sordida yielded adult males and females of all developmental stages, whereas that of $R$. neglectus yielded only adult females and nymphs in the third and fifth developmental stages. Among the captured individuals of both species, females outnumbered males. This species presents a high capacity for infesting domiciles, including those built of stone (Almeida et al., 2008; Costa and Lorenzo, 2009). Destruction of the natural environment is advantageous to T. sordida, not only because of the increased number of available viable ecotopes, but also due to the reduction or even elimination of competitors (Mendes et al., 2008). Other studies have shown that in Minas Gerais State, niches previously occupied by $T$. infestans were subsequently occupied by $T$. sordida, demonstrating a clear example of ecological succession (Forattini et al., 1979; Diotaiuti et al., 1995).

Observations at the notification sites revealed several ecotopes, including intradomiciliary and peridomiciliary ecotopes, the external environment of the house, as well as bird nests and domestic animal shelters. All of these sites showed a predominance of $T$. sordida when compared to $R$. neglectus. However, T. sordida presented higher peridomiciliary incidence while $R$. neglectus was more frequently observed inside houses. In natural environments, $T$. sordida is frequently associated with birds (Costa et al., 2003), hence its predominance in peridomiciliary environments. This species frequently replaces $T$. infestans in peridomiciliary environments (Diotaiuti et al., 1998; Tanowitz et al., 2011). Although generally associated with palm trees, $R$. neglectus can invade artificial ecotopes, probably as a result of attraction to light, when there is an ecological imbalance resulting from deforestation of the natural environment and a subsequent reduction in food resources (Costa and Lorenzo, 2009). These data suggest the possibility of the formation of new colonies, which can generate a new re-infestation process.

T. sordida presents a diploid number of chromosomes, $2 \mathrm{n}=20 \mathrm{~A}+\mathrm{XY}$ (Schreiber and Pellegrino, 1950). However, the present analysis of mutant organisms revealed peculiar behavior during meiosis: chromosomes condensed and did not show chiasms, chromatin bridges were observed between the autosomes, and some homologous chromosomes did not 
pair. Cytogenetic analysis of $T$. infestans mutants was also recently conducted in a previous study that revealed spontaneous fusion and an extra autosomal chromosome in these organisms (Poggio et al., 2013).

Noireau et al. (1998) proposed that cryptic speciation is occurring among populations of Chicago-Bolivian T. sordida, based on evidence of reproductively isolated populations. The authors suggested that there was a recent evolutionary divergence between populations, since the index of hybridization was 3\%. Our results support the hypothesis of cryptic speciation as the cytogenetic characteristics described herein can result in the formation of unviable sperm, which decreases the reproductive capacity of these mutant organisms, and thus can function as a reproductive barrier.

In the period between 2004 and 2011, there was variation in the number of triatomine reports in the northwest region of the state, with an increase from 2004 onward, and a significant peak in 2005 relative to the previous and subsequent years. This year coincided with the outbreak of Chagas disease in Santa Catarina State that was transmitted by ingestion of sugarcane juice and consumption of açai juice in northern Brazil (Jurberg et al., 2004). These data suggest that massive media publicity following this outbreak likely caused an increase in entomological surveillance by the human population, which might explain the greater number of triatomine specimens reported in 2005, and reduction in surveillance may have diminished the number of cases in subsequent years.

The present study also provided data of Chagas patients of both genders between 0 to 90 years of age, who were all born in and residents of the northwest region of the São Paulo State. The results showed that young individuals ( $0-50$ years old) presented the disease. The hospital data showed that Chagas disease was the principal cause of cardiomyopathy in this population. These high-risk patients may need high-cost therapies, such as an implantable cardioverter-defibrillator and heart transplantation, further contributing to the economic burden posed by Chagas disease for the regional economy (Cardinalli-Neto et al., 2006; AbadFranch et al., 2009). These results demonstrate the continuing persistence of chagasic patients, especially young individuals, suggesting that the disease is still active in this region and affects a high number of individuals who only discover that they are carriers when they manifest typical symptoms or are affected by other concomitant pathologies. The fact that patients with chronic Chagas disease were living at the same house in which infected triatomine were found suggests a possible transmission of the disease in the northwest region of the richest state of Brazil. These results also demonstrate the extreme importance of epidemiological vigilance and accurate mapping of the occurrence of triatomines, domiciliary infestations, and infection rates in understanding the threats caused by vector transmission. Knowledge of the triatomine fauna and their biogeographical patterns may inform essential strategies for the control of triatomines and possible risks of infection by Chagas disease.

In conclusion, our study suggests that Chagas disease is not yet under control in Brazil. Furthermore, we suggest that cryptic speciation may be occurring in populations of T. sordida from Brazil. Further studies are necessary to understand the mechanisms driving these phenomena.

\section{ACKNOWLEDGMENTS}

Research supported by Fundação de Amparo à Pesquisa do Estado de São Paulo (FAPESP) and Conselho Nacional de Desenvolvimento Científico e Tecnológico (CNPq). 


\section{REFERENCES}

Abad-Franch F, Monteiro FA, Jaramillo ON, Gurgel-Goncalves R, et al. (2009). Ecology, evolution, and the long-term surveillance of vector-borne Chagas disease: a multi-scale appraisal of the tribe Rhodniini (Triatominae). Acta Trop. 110: 159-177.

Alevi KC, Mendonca PP, Succi M, Pereira NP, et al. (2012a). Karyotype and spermatogenesis in Triatoma lenti (Hemiptera: Triatominae), a potential Chagas vector. Genet. Mol. Res. 11: 4278-4284.

Alevi KC, Mendonca PP, Pereira NP, Rosa JA, et al. (2012b). Karyotype of Triatoma melanocephala Neiva and Pinto (1923). Does this species fit in the Brasiliensis subcomplex? Infect. Genet. Evol. 12: 1652-1653.

Alevi KCC, Rosa JA and Azeredo Oliveira MTV (2013a). Mini Review: Karyotypic Survey in Triatominae Subfamily (Hemiptera, Heteroptera). Entomol. Ornithol. Herpetol. 2: 106.

Alevi KC, Mendonca PP, Pereira NP, Guerra AL, et al. (2013b). Distribution of constitutive heterochromatin in two species of triatomines: Triatoma lenti Sherlock and Serafim (1967) and Triatoma sherlocki Papa, Jurberg, Carcavallo, Cerqueira \& Barata (2002). Infect. Genet. Evol. 13: 301-303.

Alevi KCC, Mendonça PP, Pereira NP, Rosa JA, et al. (2013c). Spermatogenesis in Triatoma melanocephala (Hemiptera: Triatominae). Genet. Mol. Res. 12: 4944-4947.

Alevi KC, Mendonca PP, Pereira NP, Fernandes AL, et al. (2013d). Analysis of spermiogenesis like a tool in the study of the triatomines of the Brasiliensis subcomplex. C. R. Biol. 336: 46-50.

Alevi KCC, Mendonça PP, Pereira NP and Rosa JA (2013e). Heteropyknotic filament in spermatids of Triatoma melanocephala and T. vitticeps (Hemiptera, Triatominae). Inv. Rep. Dev. DOI: http://dx.doi.org/10.1080/0792425 9.2013.793623.

Almeida PS, Ceretti JW, Obara MT, Santos HR, et al. (2008). Survey of Triatominae (Hemiptera: Reduviidae) fauna in domestic environments and natural infection by Trypanosomatidae in the State of Mato Grosso do Sul. Rev. Soc. Bras. Med. Trop. 41: 374-380.

Bestetti RB and Theodoropoulos TA (2009). A systematic review of studies on heart transplantation for patients with endstage Chagas' heart disease. J. Card. Fail. 15: 249-255.

Bonfante-Cabarcas R, Rodriguez-Bonfante C, Vielma BO and Garcia D (2011). Seroprevalencia de La infección por Trypanosoma cruzi y factores asociados en un área endémica de Venezuela. Cad. Saúde Pública 27: 1917-1929.

Cardinalli-Neto A, Greco OT and Bestetti RB (2006). Automatic implantable cardioverter-defibrillators in Chagas' heart disease patients with malignant ventricular arrhythmias. Pacing Clin. Electrophysiol. 29: 467-470.

Costa J and Lorenzo M (2009). Biology, diversity and strategies for the monitoring and control of triatomines - Chagas disease vectors. Mem. Inst. Oswaldo Cruz 104 (Suppl 1): 46-51.

Costa J, Almeida CE, Dotson EM, Lins A, et al. (2003). The epidemiologic importance of Triatoma brasiliensis as a Chagas disease vector in Brazil: a revision of domiciliary captures during 1993-1999. Mem. Inst. Oswaldo Cruz 98: 443-449.

De Vaio ES, Grucci B, Castagnino AM and Franca ME (1985). Meiotic differences between three triatomine species (Hemiptera:Reduviidae). Genetica 67: 185-191.

Dias JCP and Schofield CJ (1998). Controle da transmissão transfusional da doença de Chagas na Iniciativa do Cone Sul. Rev. Soc. Bras. Med. Trop. 31: 373-383.

Dias JCP, Prata A and Schofield CJ (2002). Doença de Chagas na Amazônia: esboço da situação atual e perspectivas de prevenção. Rev. Soc. Bras. Med. Trop. 35: 669-678.

Diotaiuti L, Pereira AS, Loiola CF, Fernandes AJ, et al. (1995). Inter-relation of sylvatic and domestic transmission of Trypanosoma cruzi in areas with and without domestic vectorial transmission in Minas Gerais, Brazil. Mem. Inst. Oswaldo Cruz 90: 443-448.

Diotaiuti L, Azeredo BV, Busek SC and Fernandes AJ (1998). Control of Triatoma sordida in rural peri-domestic environment of the Porteirinha municipality, Minas Gerais, Brazil. Rev. Panam. Salud. Publica 3: 21-25.

Forattini OP, Ferreira OA, da Rocha e Silva EO and Rabello EX (1979). Ecological aspects of South American trypanosomiasis. XV. Development, variation and permanence of Triatoma sordida, Panstrongylus megistus and Rhodnius neglectus in artificial ecotopes. Rev. Saude Publica 13: 220-234.

Galvão C, Carcaballo RU, Rocha DS and Jurberg J (2003). A checklist of the current valid species of the subfamily Triatominae Jeannel, 1919 (Hemíptera, Reduviidae) and their geographical distribution, with nomenclatural and taxonomic notes. Zootaxa 202: 1-36.

Guerri-Guttenberg RA, Grana DR, Ambrosio G and Milei J (2008). Chagas cardiomyopathy: Europe is not spared! Eur. Heart J. 29: 2587-2591.

Jurberg J, Galvão C, Noireau F and Carcavallo RU (2004). Uma iconografia dos triatomíneos (Hemíptera: Reduviidae). Entomol. Vector. 11: 457-494. 
Mendes PC, Lima SC, Paula MBC and Souza AA (2008). Chagas disease and the space distribution of captured triatomine in Uberlândia, Minas Gerais - Brazil. Rev. Bras. Geografia Med. Saúde 3: 176-204.

Miles MA, Feliciangeli MD and de Arias AR (2003). American trypanosomiasis (Chagas' disease) and the role of molecular epidemiology in guiding control strategies. BMJ 326: 1444-1448.

Noireau F, Gutierrez T, Zegarra M, Flores R, et al. (1998). Cryptic speciation in Triatoma sordida (Hemiptera:Reduviidae) from the Bolivian Chaco. Trop. Med. Int. Health 3: 364-372.

Ostfeld RS, Glass GE and Keesing F (2005). Spatial epidemiology: an emerging (or re-emerging) discipline. Trends Ecol. Evol. 20: 328-336.

Panzera F, Perez R, Panzera Y, Alvarez F, et al. (1995). Karyotype evolution in holocentric chromosomes of three related species of triatomines (Hemiptera-Reduviidae). Chromosome. Res. 3: 143-150.

Panzera F, Hornos S, Pereira J, Cestau R, et al. (1997). Genetic variability and geographic differentiation among three species of Triatomine bugs (Hemiptera-Reduviidae). Am. J. Trop. Med. Hyg. 57: 732-739.

Pérez R, Panzera Y, Scafiezzo S, Mazzella MC, et al. (1992). Cytogenetics as a tool for triatomine species distinction (Hemiptera-Reduviidae). Mem. Inst. Oswaldo Cruz 87: 353-361.

Poggio MG, Gaspe MS, Papeschi AG and Bressa MJ (2013). Cytogenetic study in a mutant of Triatoma infestans (Hemiptera: Reduviidae) carrying a spontaneous autosomal fusion and an extra chromosome. Cytogenet. Genome Res. 139: 44-51.

Schreiber G and Pellegrino J (1950). Heteropycnosis of the autosomes as possible mechanism of speciation: cytological research in some Neotropical Hemiptera. Sci. Genet. 3: 215-226.

Silveira AC and Dias JC (2011). The control of vectorial transmission. Rev. Soc. Bras. Med. Trop. 44 (Suppl 2): 52-63.

Souza DO and Chaves GC (2009). Cem anos de negligência. Sci. Am. Bras. 8: 69-73.

Tanowitz HB, Weiss LM and Montgomery SP (2011). Chagas disease has now gone global. PLoS Negl. Trop. Dis 5: e1136.

Tarleton RL, Reithinger R, Urbina JA, Kitron U, et al. (2007). The challenges of Chagas Disease - grim outlook or glimmer of hope. PLoS Med. 4: e332.

Ueshima N (1966). Cytotaxonomy of the Triatominae (Reduviidae, Hemiptera). Chromosoma 18: 97-122.

Vallejo GA, Guhl F and Schaub GA (2009). Triatominae - Trypanosoma cruzi/T. rangeli: Vector-parasite interactions. Acta Trop. 110: 137-147. 